\title{
A Parametric Study on the Buckling Behavior of Square Steel Plates under Uniaxial Compression
}

\author{
Mazen Ali Musmar \\ School of Engineering, The University of Jordan, Amman, Jordan \\ Received July 18, 2021; Revised October 23, 2021; Accepted November 11, 2021
}

\section{Cite This Paper in the following Citation Styles}

(a): [1] Mazen Ali Musmar, "A Parametric Study on the Buckling Behavior of Square Steel Plates Under Uniaxial Compression," Civil Engineering and Architecture, Vol. 9, No. 7, pp. 2292 - 2302, 2021. DOI: 10.13189/cea.2021.090717.

(b): Mazen Ali Musmar (2021). A Parametric Study on the Buckling Behavior of Square Steel Plates Under Uniaxial Compression. Civil Engineering and Architecture, 9(7), 2292 - 2302. DOI: 10.13189/cea.2021.090717.

Copyright $\mathrm{C} 2021$ by authors, all rights reserved. Authors agree that this article remains permanently open access under the terms of the Creative Commons Attribution License 4.0 International License

\begin{abstract}
Steel plates are common in thin walled structures. They are used in various forms and geometries such as intact (not perforated) plates, stiffened plates, perforated, or perforated stiffened plates. This study employs nonlinear pushover finite element analysis to determine the critical buckling strength as well as the plate maximum strength for uniaxially square plates in the form of intact, stiffened, perforated, as well as perforated stiffened plates under uniaxial uniform compression. Curves representing the load axial displacement relationship as well as load buckling relationship were plotted. Tables summarizing the plate critical buckling strength and the plate maximum strength for each of the four plate forms were presented in order to specify the controlling failure for each form, which is considered as a vital factor for the design process. The study indicates that the critical buckling stress for stiffened plates always increases as the number of stiffeners increases. Nonetheless the critical buckling stress decreases as the number of perforations increases. Thus, a stiffened perforated plate would be a proper solution if perforations are unavoidable. The study concluded that in both stiffened square plates and in stiffened perorated plates, the ratio of the plate area to the sum of stiffeners areas tentatively indicate the possible occurrence of stiffener tripping. Ansys software was utilized to perform the analysis that was validated in calculating the critical buckling strength as well as maximum plate strength of intact plate subjected to axial compression.
\end{abstract}

Keywords Plate Buckling Analysis, Nonlinear Buckling, Square Plates

\section{Introduction}

Buckling is a mode of failure that may take place when the plate is subjected to a compressive load. On performing nonlinear buckling analysis, it is found that subsequent to critical buckling, the axial compressive load may either experience no alteration while the axial displacement increases, or starts to decrease while the axial displacement increases, or the load may increase while the axial displacement also increases, leading to a second buckling cycle [1]. Post buckling analysis involves large displacement owing to geometric nonlinearity as well as material nonlinearity in which the steel behaves as elasto-plastic material based on the level of loading and the material constitutive model.

When buckling takes place, the plate neutral plane deforms in half sine wave shapes depending on the plate aspect ratio, perforations, stiffeners and boundary conditions [2]. Buckling results in development of membrane plate stresses due to the stretching of the plate neutral plane, when the unloaded side edges are constrained. The resulting tensile stresses hinder lateral out of plane deflection. In this regard a number of researches have been carried out on buckling of rectangular plates. Research studies have been published on plates with cut-outs subjected to in plane axial edge loading [3]. They indicate that in such cases the critical buckling strength is usually larger than the plate load carrying strength especially when large cutouts exist. 
Komur and Sonmez [4] stated that the existence of perforations modifies the buckling modal shape. According to Kim et al. [5], cutouts weaken the buckling strength as well as load carrying capacity. In the case of large perforations, the critical buckling strength becomes larger than the plate ultimate strength. According to Saad-Eldeen et al. [6], a perforated plate may experience yielding and buckling that may lead to fractures.

The essential factors that govern the plate carrying strength is its slenderness, its thickness as well as the material mechanical properties such as elastic modulus, yield stress and the material constitutive relationship. Gunay et al. [7] studied the nonlinear buckling behavior of stiffened plates, they concluded that the global half wave buckling of an unstiffened plate changes to several half waves local buckling. They also concluded that critical buckling stress values increase proportionally with the number of stiffeners. Instability may occur owing to lateral torsional buckling of stiffeners, referred to as tripping; or by virtue of plate local buckling that ends up into global buckling of the stiffened plate when the critical buckling stress is at the same level of the local buckling stress. The ratio of torsional stiffness of the stiffener to plate bending stiffness is a controlling factor that leads the failure mode towards stiffener tripping or plate buckling.

Stiffened plates are considered cost effective when designed to allow for plate local buckling between the adjacent stiffeners at a fraction of the failure load. Such post buckling capacity enhances the critical buckling strength and at the same time permits savings in material weight [8]. The large deflection behavior of steel plates is a highly nonlinear problem.

Few studies in literature adopted plate slenderness values (width/thickness) between 90 to 110 to carry out nonlinear push over finite element analysis that aimed at comparing the buckling behavior of square plates in the forms of intact, perforated, stiffened as well as stiffened perforated square plates subjected to a uniform in plane compressive loading. In this study the plate (width/thickness) ratio is 100 . At this value the plate flexural stiffness is relatively low. This study intends to cover this gap. Therefore, the objective of the current study is to carry out a nonlinear push over finite element analysis that aims at investigating the behavior of each of the aforementioned square plate forms when subjected to uniaxial concentric compressive loading that is applied on the transverse sides of the plate. The plate has simply supported edges. The consequence of the considered plate forms on the plate elastic buckling behavior, the plate post elastic buckling behavior as well as the plate load carrying strength and the controlling failure is investigated.

\section{Problem Statement}

In general, the plate may fail due to buckling instability, when the critical buckling strength is lower than the plate load carrying strength. On the other hand, the plate may experience strength failure at low out of plane deflections when the critical buckling strength is higher than the plate load carrying strength.

Finite element analysis enables the researcher to trace the plate behavior within all loading stages. Thus, the main objective of this study is to carry out a parametric study on severable available and frequently used forms of square steel plates. The plates are subjected to applied uniaxial in-plane loading (Figure 1 and Figure 2). The study embraces the following forms of square $200 \mathrm{~mm}$ plates of thickness (tp) $=2 \mathrm{~mm}$ :

- Intact (not perforated) plates.

- Stiffened plates; stiffeners depth is $20 \mathrm{~mm}$, stiffeners width (ts) is $4 \mathrm{~mm}$. The ratio of stiffener thickness to plate thickness $(\mathrm{ts} / \mathrm{tp})=2$ was adopted subsequent to several trials. Such a ratio resulted in lateral torsional buckling of stiffeners, termed tripping in one case only. While in all the remaining cases, the plates experienced plate local buckling between stiffeners.

- Perforated plates; perforations diameter $(\mathrm{d})=30 \mathrm{~mm}$.

- Perforated stiffened plates; the stiffeners are identical to the stiffeners in stiffened plates, while perforations are similar to those in perforated plates.

All the plate edges are simply supported, kept straight in the out of plane direction. 

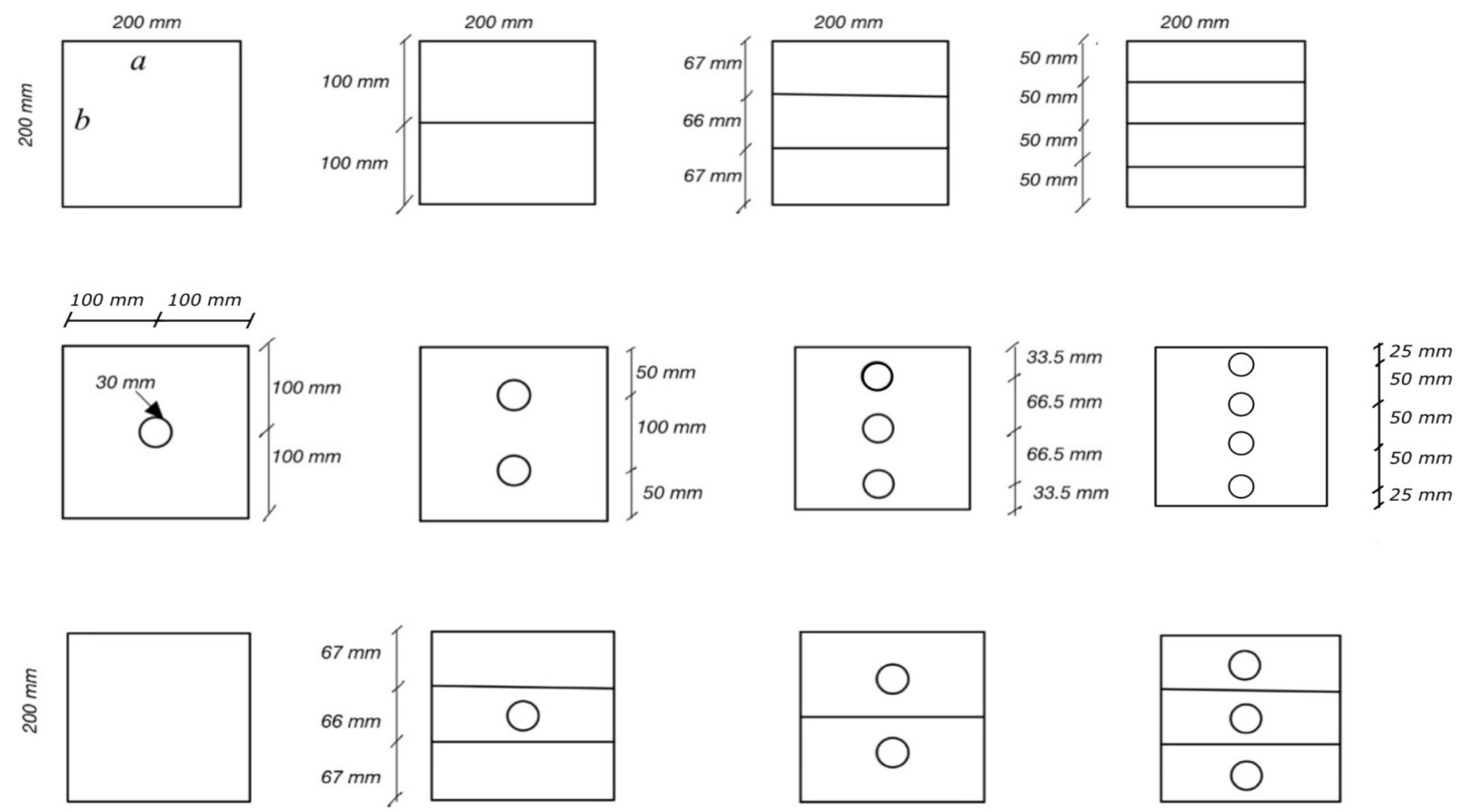

Figure 1. Schematic sketches illustrating square intact plate, stiffened, perforated, and perforated stiffened square intact plates.
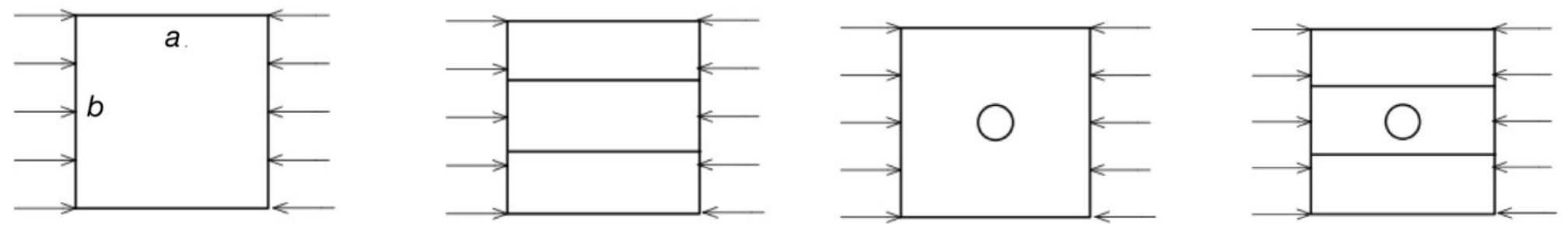

Figure 2. Schematic sketches illustrating the direction of uniformly distributed uniaxial load 
Perforations exceeding $60 \%$ of the plate area are rarely used in practice. Thus, the study is restrained to perforations having their diameter sum ranging from 0.15 up to 0.6 of the plate widths.

\section{Assumptions}

- The plate material is homogeneous. It is isotropic and the steel constitutive model is bilinear elastic perfectly plastic.

- Plane sections originally normal to the neutral plane remain normal to the neutral plane after bending.

- In Eigen buckling analysis, small deflection theory and linear elastic properties are considered. In the nonlinear post buckling analysis, large deflection is considered and the material behaves as elastic perfectly plastic.

Analysis method and Finite element model

- The study assumes that the plate and the stiffeners are rigidly connected and are composed of the same isotropic material. The plate has simply supported edges (Figure 3).

- The finite element analysis was performed in two stages. The first stage involved Eigen buckling analysis to determine the elastic buckling strength and the corresponding modal shapes.

In the second stage, the deformed shape corresponding to the elastic buckling load at the first mode of vibration in Eigen buckling analysis was implemented as the initial deformed geometry in the nonlinear buckling analysis. The nonlinear buckling analysis involves nonlinearity due to nonlinear geometry as well as due to material yielding. The critical buckling load or the critical buckling strength $\left(\mathrm{P}_{\mathrm{cr}}\right)$, is the threshold towards post buckling analysis.

A parametric study was carried out to investigate and discuss the effect of each of the aforementioned four cases on the plate buckling behavior due to incrementally applied loading up to failure.

\subsection{Finite Element Modeling}

Analysis was carried out using Ansys [9]. Shell 181 element is used. It is capable of modeling both membrane action and flexural behavior. It has four nodes. Each node has six degrees of freedom. The study assumes that the plate and the stiffeners are rigidly connected and are composed of the same isotropic elastic material. Young's modulus $=200 \mathrm{GPa}$, Poison's ratio $=0.3$, yield strength $=$ $250 \mathrm{MPa}$, ultimate strength=460 Mpa. The shell element maximum size is $b / 20$. At the vicinity of holes, it was selected to be the minimum of $\mathrm{d} / 40$ or $\mathrm{b} / 50$.

\subsection{Validation of the Finite Element Model}

In general, two kinds of errors may occur on carrying out finite element analysis. Discretization error, if the improperly sized finite elements are adopted, and modeling error on selecting the wrong element type that does not properly simulate the behavior of the investigated structural member in terms of kinematics, equilibrium and behavior. Thus, a validation analysis was carried out to ensure that the selected sizes are suitable, and that the selected element type numerically models the investigated structural member. A mesh sensitivity analysis was performed for the plate to determine the applicability of the mesh size. Finally obtained Finite element analysis results are validated for the case of intact square plate in Eigen buckling as well as nonlinear buckling analyses by comparing them with the equations presented in literature that give a closed form solution. Thereafter buckling analysis was carried for all considered simply supported square steel plate forms, subjected to uniformly distributed axial loading at the transverse edges (Figure 2 and Figure 3). Such support conditions reflect the weak rotational restraints along the thin plate edges.

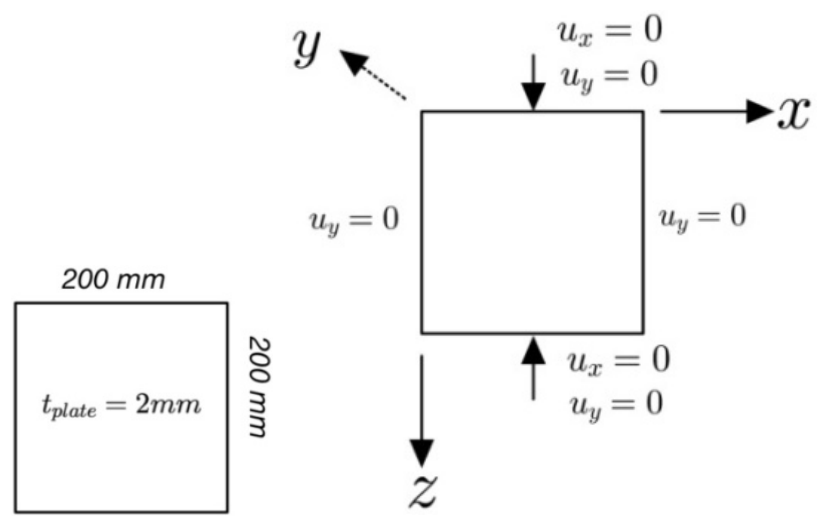

Figure 3. Plate geometry and boundary conditions

The results of the Eigen buckling analysis for intact plates were compared with closed form solutions presented in literature as well as the nonlinear buckling analysis as follows:

- Eigen buckling analysis

The obtained elastic buckling load $\left(\mathrm{P}_{\mathrm{cr}}\right)$ for the intact square plate from Finite element analysis $\left(\mathrm{P}_{\mathrm{cr}}\right)$ was found to be $28.64 \mathrm{kN}$ or $\mathrm{N}_{\mathrm{cr}}=143.2 \mathrm{~N} / \mathrm{mm}$

It is reasonably close to the critical buckling load $\mathrm{N}_{\mathrm{cr}}$ of $144.61 \mathrm{~N} / \mathrm{mm}$ for the solid square plate, obtained by equation (1) [2].

$$
\begin{aligned}
& D=\frac{E t^{3}}{12\left(1-v^{2}\right)}=\frac{2 \times 10^{5}(2)^{3}}{12\left(1-0.3^{2}\right)}=146520.146 \mathrm{~mm}^{4} \\
& N_{c r}=4 \frac{\pi^{2} D}{b^{2}}=4 \frac{\pi^{2} * 146520.146}{200^{2}}=144.61 \mathrm{~N} / \mathrm{mm}
\end{aligned}
$$

Finite element analysis: $P_{c r}=28.64 \mathrm{kN}$

$\mathrm{N}_{\mathrm{cr}}=28.64 k N^{*} 1000 / 200 \mathrm{~mm}=143.2 \mathrm{~N} / \mathrm{mm}$

- Nonlinear buckling analysis 
Maximum plate load carrying strength (plate maximum strength) for the intact $200 \mathrm{~mm}$ x $200 \mathrm{~mm}$ square plate as determined by Finite element analysis is $47.43 \mathrm{kN}$. Whereas the maximum load carrying strength as obtained according to the design equations (2) presented by Guedes [10] is $49.5 \mathrm{kN}$.

The difference is $(49.5-47.43) / 49.5=4.18 \%$

The results are reasonably close, keeping in mind that the equations that are used as design tools usually incorporate safety margins.

$$
\begin{gathered}
\lambda=\frac{b}{t} \sqrt{\frac{\sigma_{y}}{E}}=\frac{200}{2} \sqrt{\frac{250}{2.1 E 5}}=3.45 \\
\frac{\sigma_{u}}{\sigma_{y}}=\frac{a_{1}}{\lambda}-\frac{a_{2}}{\lambda \cdot 2} \quad \lambda \geq 1 \\
a_{1}=2 \quad a_{2}=1 \\
\frac{\sigma_{u}}{250}=\frac{2}{\lambda}-\frac{1}{\lambda^{2}} \\
\frac{\sigma_{u}}{250}=\frac{2}{3.45}-\frac{1}{(3.45)^{2}}=0.495 \\
\sigma_{u}=(250)(0.495)=123.9 \mathrm{MPa} \\
P_{\max }=\left(\sigma_{u}\right)(b)\left(t_{p}\right)=(123.9) \frac{(200)(2)}{1000}=49.5 \mathrm{kN}
\end{gathered}
$$

\section{Results and Discussion}

In general, in the case of beams, elastic buckling is considered as an instability mode of failure. This is not necessary the case in plate buckling as the plate is supported on four edges. Thus, Plate buckling occurs in two orthogonal directions.

The plate may fail either due to buckling instability owing to excessive buckling when the critical buckling strength is less than the maximum load carrying strength (plate maximum strength), or due to strength failure when the critical buckling strength is larger than the plate load carrying strength.

The analysis indicated that buckling instability is the main cause of failure in the case of the intact plate. Beyond the critical buckling strength, the plate experiences nonlinear post buckling due to geometric nonlinearity, followed by material nonlinearity when Von Mises stresses $\left(\sigma_{\mathrm{e}}\right)$ surpass the material yield stress. Eventually the failure occurs based on kinematic instability due to excessive buckling. On the other hand, analysis results indicated that this may not be the case in perforated plates with large openings. In such a case, the developed internal load within plate net cross section which is a fraction of the gross section, may not balance the applied axial load even at low out of plane deflection values, resulting in strength failure.

In the case of the stiffened plates, finite element analysis indicated that instability was experienced in the form of tripping only in the case of a single stiffener plate at a ratio of stiffener thickness to plate thickness ( $t s$ / $t p)=2$. In all other cases, the relatively large torsional stiffness of the stiffeners compared to the bending stiffness of the plate suppressed the occurrence of tripping. In the remaining cases, instability was in the form of plate local buckling between the two adjacent stiffeners.

The maximum load carrying strength of the plate or the plate maximum strength is the peak point in the curve representing the load versus in plane shortening.

The first mode of vibration requires the least energy. Thus, the plate neutral plane deformations associated with the first mode of vibration in the Eigen buckling analyses pertaining to all considered cases were considered as the initial imperfections in the plate geometry for the nonlinear large deflection analyses. The Finite element analysis was carried out using Ansys [9].

\section{Parametric Study}

Among the most relevant parameters affecting the buckling behavior of uni-axially loaded plates are stiffeners, perforations, edge boundary conditions, surface imperfections.

This parametric study investigates the buckling behavior corresponding to the following parameters:

- Effect of stiffeners.

- Effect of perforations.

- Effect of perforations on stiffened plates.

\subsection{Effect of Stiffeners}

Three cases are considered:

- Providing one stiffener giving $\mathrm{Ap} / \mathrm{As}=5$

- Providing two stiffeners giving $\mathrm{Ap} / \mathrm{As}=2.5$

- Providing three stiffeners giving $\mathrm{A}_{\mathrm{p}} / \mathrm{A}_{\mathrm{s}}=1.67$

Figure 4 shows the modal shapes corresponding to the first mode of vibration for the intact square plate, single stiffener, two stiffeners and three stiffeners square plates respectively. The modal shapes were determined using Eigen buckling analysis. It is clear that providing stiffeners modifies the plate modal shape. The global half wave buckling of the intact plate changes to several local buckling half waves based on the number of stiffeners. The buckling in the intact plate is in the form of one-half wave in the two orthogonal plate dimensions, whereas in the case of one stiffener plate buckling is in the form of two half waves. For two stiffeners plates and three stiffeners plates, the plate experiences multiple half waves. The more the number of half waves is, the less is the wave length, and the higher is the plate stiffness.

Figure 5 and Figure 6 illustrate the load end shortening relationship and the load buckling relationship for intact square plate, one, two, and three stiffeners square plates respectively. Table 1 summarizes the analysis results. 
The maximum strengths for intact plate, one stiffener plate with $\mathrm{Ap} / \mathrm{As}=5$, two stiffeners plate with $\mathrm{Ap} / \mathrm{As}=$ 2.5 , three stiffeners plate with $\mathrm{Ap} / \mathrm{As}=1.67$ are $47.43 \mathrm{kN}$, $82.3 \mathrm{kN}, 130.1 \mathrm{kN}, 141.9 \mathrm{kN}$. The increase in strength with respect to the intact plate is $73.5 \%, 174 \%, 199.2 \%$.

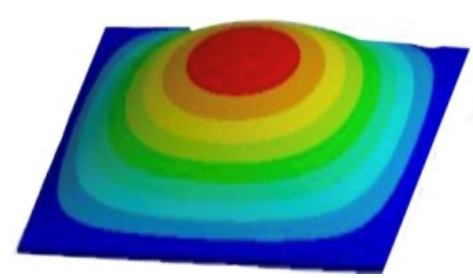

a.

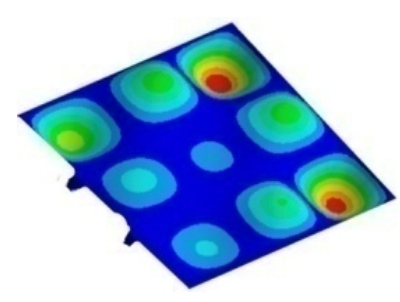

c.

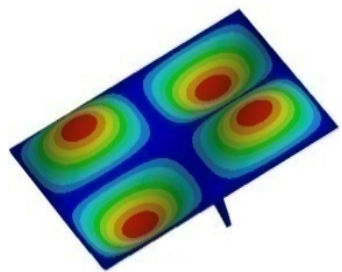

b.

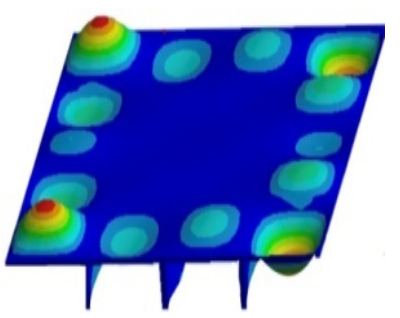

d.

Figure 4. First modal vibration mode shapes for a. intact square plates, one, two and three stiffeners square plates.

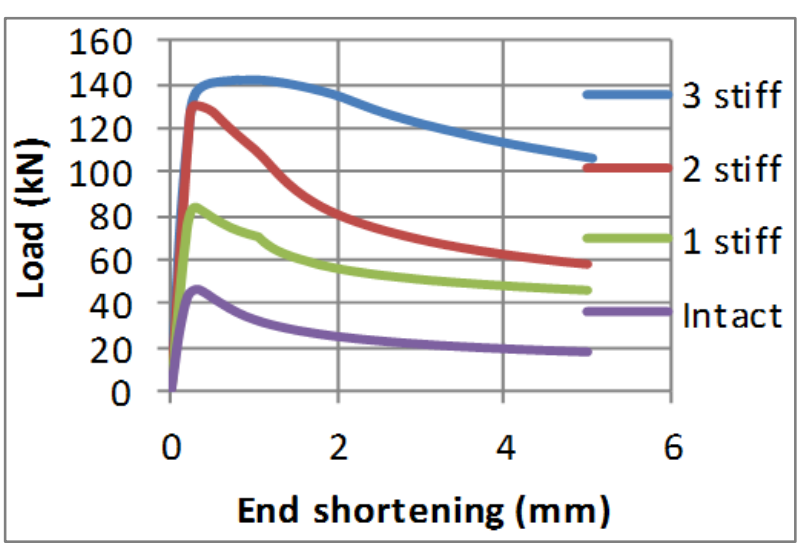

Figure 5. Load end shortening relationship

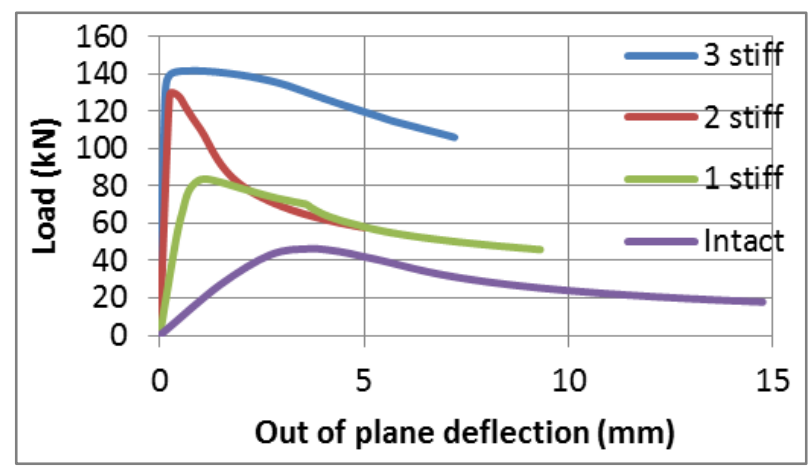

Figure 6. Load buckling relationship

The only case where stiffener tripping took place was that of one stiffener plate with $\mathrm{Ap} / \mathrm{As}=5$ (Figure7).

Stiffener tripping was experienced when the sum of lateral torsional stiffness of the stiffeners is less than the plate flexural stiffness.

In the case of one stiffener two perforations plate, no stiffener tripping was experienced as the stiffener torsional stiffness became larger than the plate flexural stiffness of the net plate cross section after providing two perforations. In this case the ratio of $\mathrm{Ap} / \mathrm{As}=3.50$.

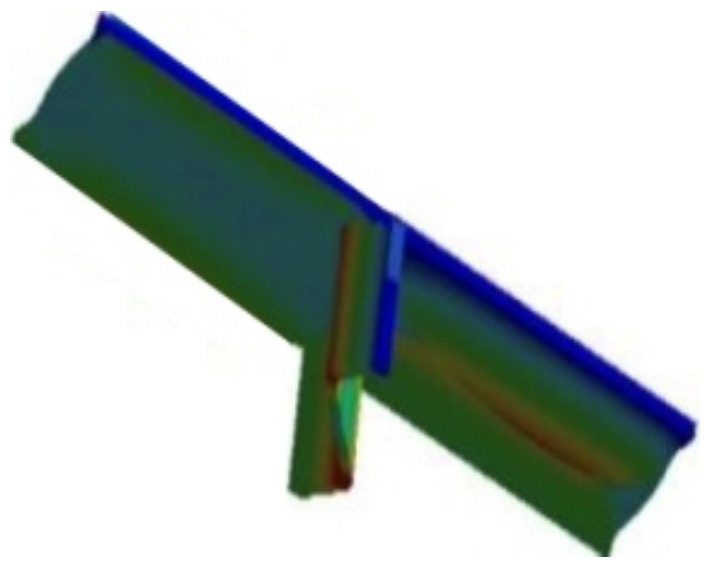

Figure 7. Stiffener tripping in a stiffened square plate

Table 1. Summary of results

\begin{tabular}{|c|c|c|c|c|c|}
\hline Plate form & $\begin{array}{c}\text { Critical buckling } \\
\text { strength }\end{array}$ & $\begin{array}{c}\text { Out of plane } \\
\text { deflection }\end{array}$ & $\begin{array}{c}\text { Maximum } \\
\text { strength } \mathbf{P}_{\max }\end{array}$ & $\begin{array}{c}\text { End shortening at } \\
\mathbf{P}_{\max }\end{array}$ & $\begin{array}{c}\text { Out of plane } \\
\text { deflection }\end{array}$ \\
\hline & $\mathrm{kN}$ & $\mathrm{mm}$ & $\mathrm{kN}$ & $\mathrm{mm}$ & $\mathrm{mm}$ \\
\hline Intact plate & 28.64 & 1.50 & 47.43 & 0.30 & 3.78 \\
\hline One Stiffener & - & - & 82.3 & 0.27 & 0.97 \\
\hline Two stiffeners & - & - & 130.1 & 0.21 & 0.54 \\
\hline Three stiffeners & - & - & 141.9 & 0.80 & 0.60 \\
\hline
\end{tabular}




\subsection{Effect of Perforations}

Figure 8 illustrates the modal shapes for one opening, two openings, three openings, and four openings perforated plates. The corresponding diameter sum ratio to plate width is $0.15,0.30,0.45,0.6$ respectively.

Table 2 indicates that the critical buckling strength for the intact plate is $28.64 \mathrm{kN}$. It decreases to $26.1 \mathrm{kN}, 25.8$ $\mathrm{kN}, 24.8 \mathrm{kN}$, and $20.9 \mathrm{kN}$ for one, two, three, and four openings perforated plates respectively. The decrease in critical buckling strength is $8.8 \%, 9.9 \%, 13.4 \%, 27 \%$ respectively. The intact plate max strength is $47.43 \mathrm{kN}$. It decreases to $44.8 \mathrm{kN}, 42.18 \mathrm{kN}, 40.8 \mathrm{kN}$, and $26.4 \mathrm{kN}$ for one opening, two openings, three openings, and four openings perforated plates respectively. The decrease in the plate maximum strength is $5.5 \%, 11.1 \%, 14 \%, 44.3 \%$ respectively. In all cases, the critical buckling strength is less than the plate maximum strength.

Figure 9 and Figure 10 indicate that all the considered perforated plates experienced linear buckling up to the critical buckling strength, which is the threshold towards post buckling stage that began with geometric nonlinearity, which in turn led to more buckling, and material nonlinearity. Eventually the plate experienced buckling instability owing to excessive buckling. This is not a desirable mode of failure as it is a sudden and without warning.
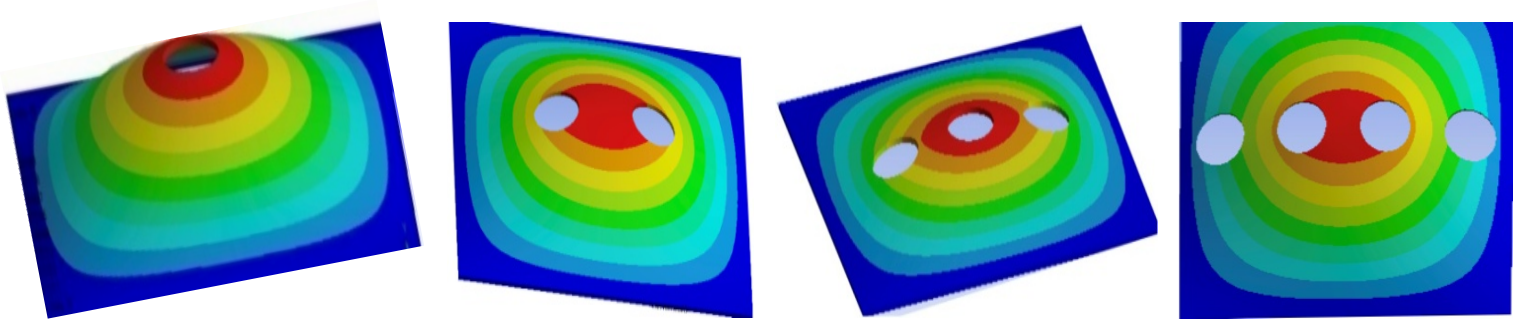

Figure 8. First modal vibration mode shapes for the perforated square plates

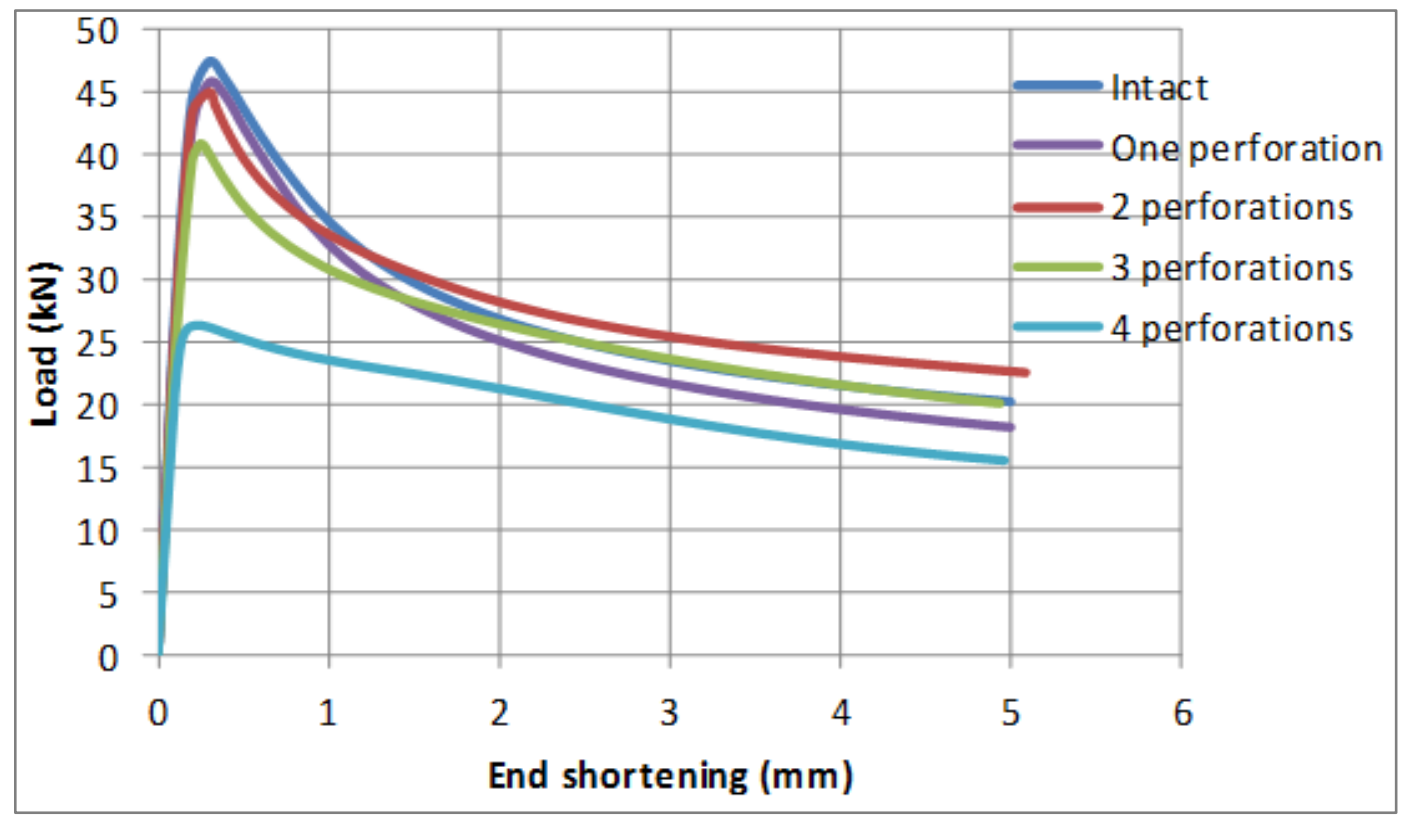

Figure 9. Load end shortening relationship 


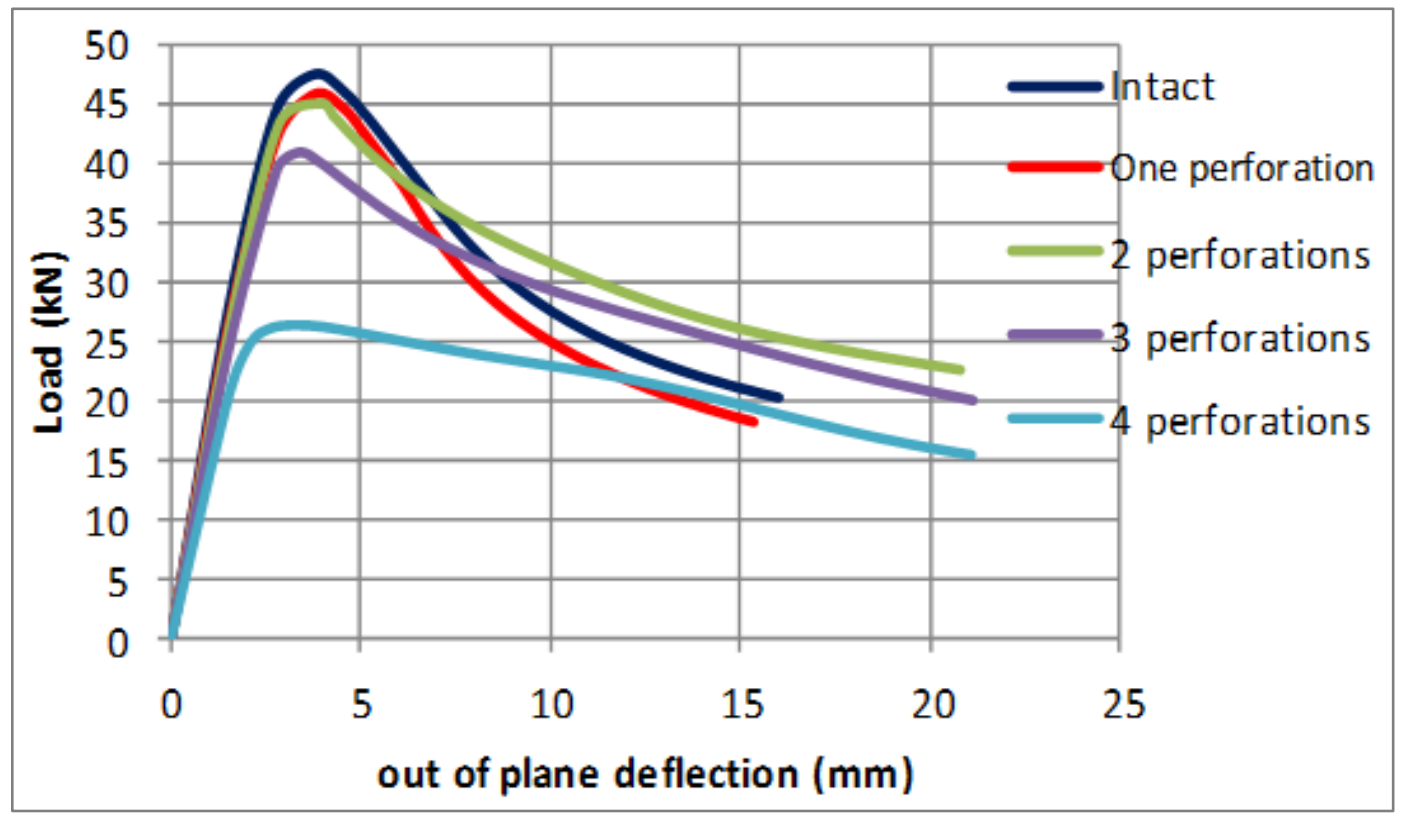

Figure 10. Load buckling relationship

Table 2. Summary of analysis results for intact and perforated plates

\begin{tabular}{|c|c|c|c|c|c|}
\hline Plate form & $\begin{array}{c}\text { Critical } \\
\text { buckling } \\
\text { load }\end{array}$ & $\begin{array}{c}\text { Out of plane } \\
\text { deflection }\end{array}$ & $\begin{array}{c}\text { Maximum strength } \\
\text { Pmax }\end{array}$ & $\begin{array}{c}\text { End shortening } \\
\text { at Pmax }\end{array}$ & $\begin{array}{c}\text { Lateral } \\
\text { deflection at } \\
\text { Pmax }\end{array}$ \\
\hline & $\mathrm{kN}$ & $\mathrm{mm}$ & $\mathrm{kN}$ & $\mathrm{mm}$ & $\mathrm{mm}$ \\
\hline Intact plate & 28.64 & 1.50 & 47.43 & 0.30 & 3.78 \\
\hline Single perforation & 26.1 & 1.53 & 44.80 & 0.30 & 3.79 \\
\hline Two perforations & 25.8 & 1.54 & 42.18 & 0.29 & 3.90 \\
\hline Three perforations & 24.8 & 1.54 & 40.8 & 0.25 & 3.38 \\
\hline Four perforations & 20.9 & 1.56 & 26.4 & 0.22 & 2.10 \\
\hline
\end{tabular}

Figure 9 and Figure 10 indicate that the shape of the buckling behavior for all other cases has maintained a similar pattern. Critical buckling strength was 0.5 to 0.8 of plate maximum strength. Subsequently post buckling stage began with nonlinear buckling due to geometric nonlinearity to about 0.9 to 0.92 of plate maximum strength, beyond which material nonlinearity began as more steel Von Mises stresses $\left(\sigma_{\mathrm{e}}\right)$ within the mostly stressed regions fell on the yield surface resulting in excessive buckling which in turn led to sudden kinematic based buckling instability.

\subsection{Effect of Perforations on Stiffened Plates}

Figure 12, Figure 13 and Table 3 indicate that the increase in plate maximum strength for two stiffeners, two stiffeners with single perforation, two stiffeners with three perforations, one stiffener, and one stiffener with two perforations are $174 \%, 134 \%, 101 \%, 73.5 \%, 69.2 \%$ respectively, compared to that of the intact plate. Figure 11 illustrates the modal shape corresponding to the first mode of vibration for plates having two stiffeners with no perforations; two stiffeners with one perforation; two stiffeners with three perforations; one stiffener with no perforations; and one stiffener with two perforations respectively. Figure 12 and Figure 13 illustrate the load end shortening and the load buckling relationships respectively for the intact plate as well as the aforementioned plate forms. Buckling is experienced when the out of plane deflection is relatively large, compared to the plate thickness. Table 3 summarizes the analysis results. Stiffener tripping was experienced in the one stiffener plate with $\mathrm{Ap} / \mathrm{As}=5$, Nonetheless in one stiffener two perforations plate with $\mathrm{Ap} / \mathrm{As}=3.5$, the plate did not experience any stiffener tripping as the two openings led to a lower value of the plate flexural stiffness than the stiffener torsional stiffness.

The analysis results indicate that all the considered stiffened plates had their plate buckling strength larger than the plate maximum strength. As the applied load became more, the plate response remained linear elastic. The threshold of this stage was when the steel Von Mises 
stresses $\left(\sigma_{e}\right)$ and especially in the vicinity of perforations fell on the material yield surface. The steel constitutive model is elasto plastic, so the plate experienced Plastic deformation that led the to redistribution of stresses, enabling the plate section to develop more internal load to balance the applied load. Eventually the developed internal load resultant was unable to balance the applied load. It is a gradual failure with ample warning owing to material plasticity. It is a desirable behavior compared to that of unstiffened thin plates which experienced a sudden and without warning kinematic based buckling instability.
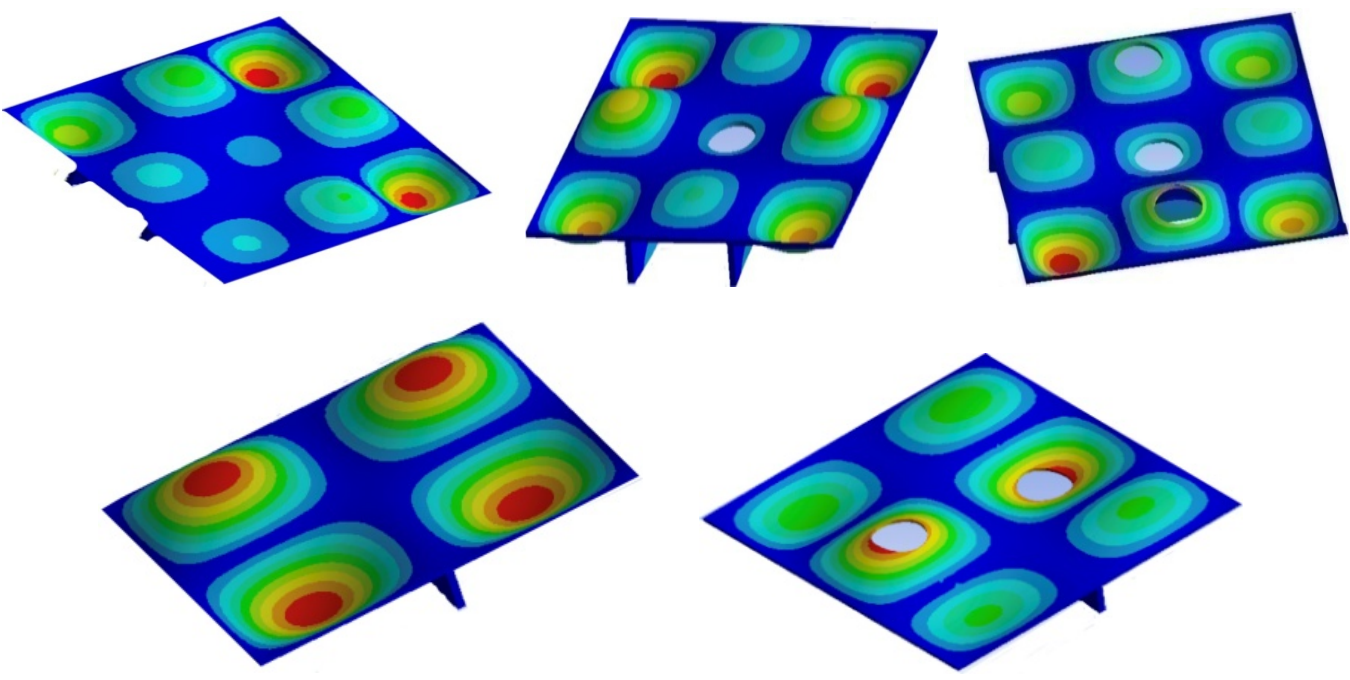

Figure 11. First modal vibration mode shape for perforated stiffened plates

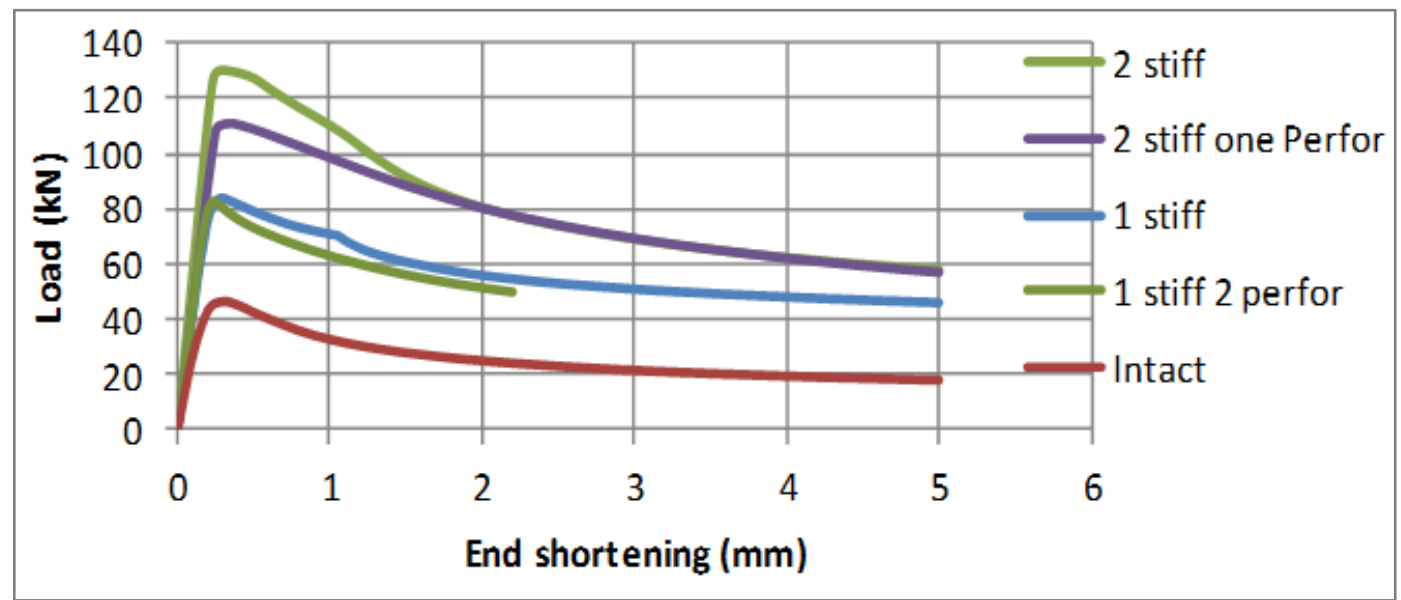

Figure 12. Load end shortening relationship 


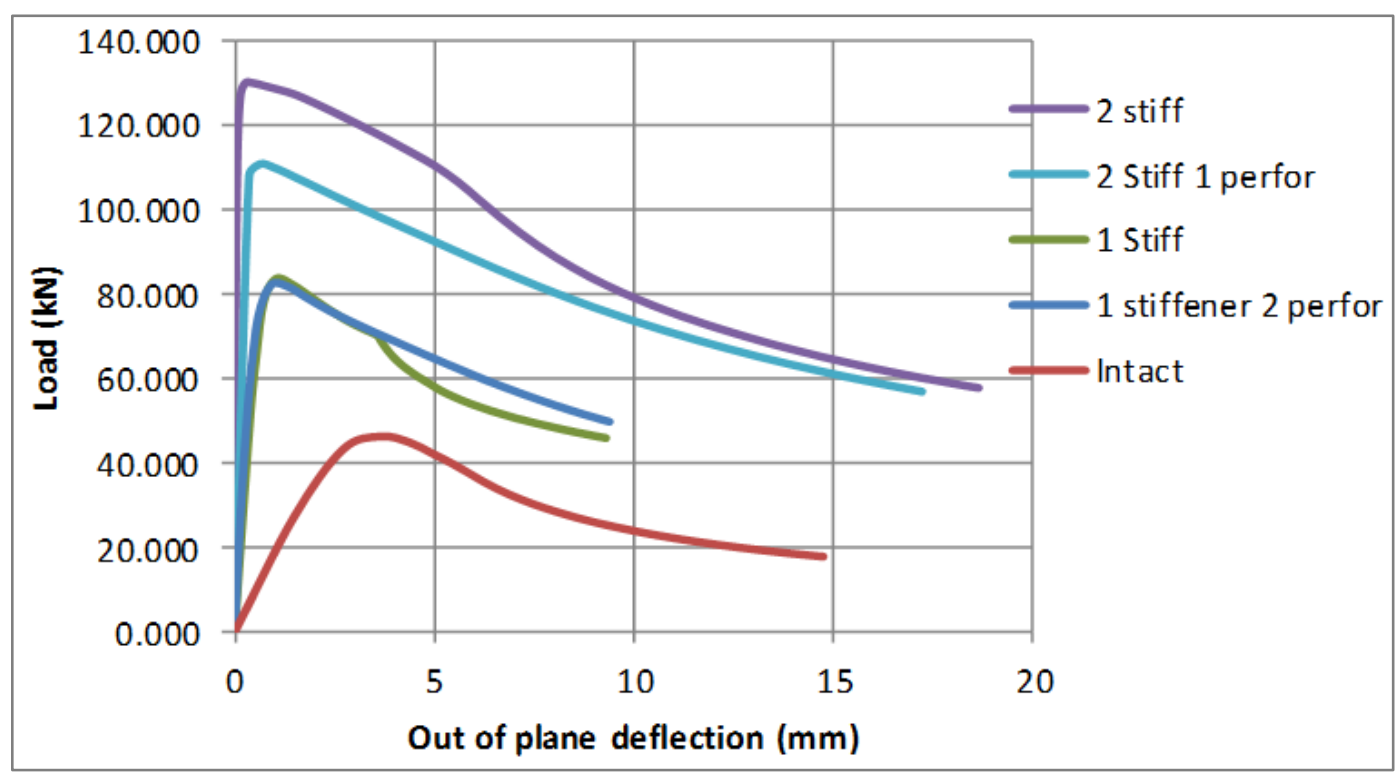

Figure 13. Load buckling relationship

Table 3. Summary of analysis results for the intact plate and perforated stiffened plates

\begin{tabular}{|c|c|c|c|c|c|}
\hline Plate form & $\begin{array}{c}\text { Critical } \\
\text { buckling load }\end{array}$ & $\begin{array}{c}\text { Out of plane } \\
\text { deflection }\end{array}$ & $\begin{array}{c}\text { Maximum } \\
\text { strength }\end{array}$ & End shortening & $\begin{array}{c}\text { Out of plane } \\
\text { deflection }\end{array}$ \\
\hline Intact plate & $\mathrm{kN}$ & $\mathrm{mm}$ & $\mathrm{kN}$ & $\mathrm{mm}$ & $\mathrm{mm}$ \\
\hline One Stiffener & 28.63 & 1.50 & 47.43 & 0.30 & 3.78 \\
\hline $\begin{array}{c}\text { One Stiffener two } \\
\text { perforations }\end{array}$ & - & - & 82.3 & 0.27 & 0.97 \\
\hline Two stiffeners & - & - & 80.26 & 0.26 & 0.94 \\
\hline $\begin{array}{c}\text { Two stiffeners one } \\
\text { perforations }\end{array}$ & - & - & 130.1 & 0.21 & 0.54 \\
\hline $\begin{array}{c}\text { Two stiffeners three } \\
\text { perforations }\end{array}$ & - & - & 111 & 0.48 & 0.85 \\
\hline
\end{tabular}

\section{Conclusions}

Based on the obtained results and the written discussion, the following conclusions are presented:

- Providing stiffeners leads to the enhancement of the square plate buckling strength. When the plate buckling strength exceeds the steel plate yield strength, the material plasticity leads to plastic deformation that redistributes the stresses, and paves the way towards extending the plastic stress region in a manner that enables the plate section to develop larger internal force resultant that balances the incremental applied loading. In this case, the development of plastic deformation region offered the desired ample warning prior to failure when steel Von Mises $\left(\sigma_{e}\right)$ stresses fell on the failure surface.

- The larger the perforations diameter sum is, the less is the plate critical buckling strength as well as the plate maximum strength.
- For intact and perforated square plates subjected to uniaxial uniform compressive load, the buckling failure is elastic when the slenderness $(b / t)$ is $\geq 100$. Buckling failure is sudden and gives no warning so it is undesirable.

- A stiffened perforated plate would be a proper solution when perforations are unavoidable. Raising the square plate buckling strength beyond the material yield strength leads to the development of material plastic behavior that leads to gradual failure with ample warning.

- The ratio of plate area to the sum of stiffeners areas (Ap/As) tentatively indicates the possible occurrence of stiffener tripping.

\section{Acknowledgement}

The author is pleased to acknowledge the support of The University of Jordan. 


\section{REFERENCES}

[1] Behzad M, Eunsoo C, and Woo, J, Compressive investigation of buckling behavior of plates considering the effect of holes, 2018, Structural Engineering and Mechanics, 2018, Vol 68, No.2, pp 261-275.

[2] Ventsel E. and Krauthammer T., thin Plates and shells theory analysis and applications, Marcel Dekker Inc, 2001

[3] Grondin G.Y, Elwi A.E, Cheng J.J.R, Buckling of stiffened steel plates/ a parametric study, 1999, Journal of construction steel research, vol 50, No2, pp 151-175.

[4] Komur M. Aydin, Mustafa Sonmez, Elastic buckling behavior of rectangular plates with holes subjected to partial edge loading, Journal of Construction Steel Research, 2015, vol 112, pp 54-60.

[5] Kim Ul-Nyeon, Choe Ick-Heung, Paik Jeom Kee, Buckling and ultimate strength of perforated plate panels subject to axial compression, Taylor \& Francis, 2009, vol4, No.4, pp 337-361.

[6] Saad-Eldeen S., Garbatov Y, Guedes Soares, Ultimate strength assessment of steel plates with a large opening, 2014, Taylor and Francis Group, London, ISBN 978-1-138-00124-4

[7] Gunay E, Aygun C, Yildiz Y, Nonlinear buckling finite element analysis of stiffened steel plates, 2013, vol 669 pp450-456

[8] Quin D, Murphy, A, McEwan, W, Lemaitre, F, Stiffened panel stability behavior and performance gains with plate prismatic sub-stiffening, 2009, Thin-walled structures, 2009, Vol 12, No.2, pp 1457-1468.

[9] Ansys 2021 R1 Academic version.

[10] Guedes Soares S, Design Equation for Ship Plate Elements under uniaxial compression, J. Construct. Steel Research 1992, Vol 22, pp 99-114. 